\title{
Heavy metal elements in toiletries analyzed by INAA, ICP-MS and SEM-EDX
}

\author{
By E. Furuta ${ }^{1}$, H. Minowa ${ }^{2}$, K. Tagami ${ }^{3}$, Y. Okada ${ }^{4}$ and H. Nakahara ${ }^{5}$ \\ 1 Ochanomizu University Graduate School \\ 2 The Jikei University School of Medicine \\ 3 National Institute of Radiological Sciences \\ 4 Tokyo City University \\ 5 Tokyo Metropolitan University
}

Toiletries / Platinum, gold and silver / Impurities / INAA / ICP-MS / SEM-EDX

Summary. Recently, many toiletries claiming inclusion of platinum (Pt), silver $(\mathrm{Ag})$ and gold $(\mathrm{Au})$ as additives are sold in ordinary cosmetics shops. However, their concentrations are not clearly indicated. In the present work, these toiletries were analyzed for heavy metal elements by instrumental neutron activation analysis (INAA) and inductively coupled plasma mass spectrometry (ICP-MS), and the particle sizes were observed by scanning electron microscope (SEM) and the constitutions of the small particles were analyzed by energy dispersive X-ray spectroscopy (EDX). The concentrations of $\mathrm{Pt}$ in the toiletries observed were from 1 to $80 \mathrm{ppm}$. The lower detection limit of Pt by INAA was about $1 \mathrm{ppm}$ because of the presence of sodium in high concentrations for those samples. Consequently, some toiletries which should have had $\mathrm{Pt}$ according to the manufactures were found not to contain Pt probably because it was less than the detection limit. On the other hand, there were a few toiletries that were found to contain $\mathrm{Ag}$ although the addition of $\mathrm{Ag}$ was not mentioned by the manufactures. It is considered that these non-indicated $\mathrm{Ag}$ were included as impurities of the added $\mathrm{Au}$. The concentrations of the non-indicated $\mathrm{Ag}$ were even higher than those of the indicated Ag. A very small amount of Sr, which was nominated in the negative list of Japan, was also detected in 2 out of 5 kinds of toiletries analyzed by ICP-MS.

\section{Introduction}

According to the global trend of the synthetic management of chemical substance, it has been considered that information disclosure is necessary for the toiletries and cosmetics which are also the chemical substances daily used by human being [1]. It is adopted in Europe [2], USA and Japan that all additives to toiletries and cosmetics should be listed as a result of the action and each country adopts the notation system as global standards.

The toiletries and cosmetics are made under the regulation of law because they are directly put on the skin like medicine. For the safe use of toiletries and cosmetics, there are an addition prohibiting list even as impurities, so-called a negative list, and an addition allowing list with upper limit, so-called a positive list, for toiletries and cosmetics in many countries. However, the contents of these lists are somewhat different according to each regulation body. In Japan, the notation system of indicating all additives was introduced into toiletries and cosmetics in 2001 [3]. The manufactures of toiletries and cosmetics can add any additives except those in the negative list and those in the positive list with less than the prescribed limits. Manufactures are also responsible to any additives not mentioned in those lists, and manufactures should indicate all additives in the toiletries and cosmetics by the law. However, only qualitative notation is required, so that the concentrations of additives are not usually cited.

Recently, many toiletries such as lotion, gel and cream are found with addition of platinum $(\mathrm{Pt})$, gold $(\mathrm{Au})$ and silver $(\mathrm{Ag})$ with expectation of their beauty effects to the skin. Small pieces of shining particles are visible in some toiletries claiming Au added. On the other hand, there are not visible shining particles in the toiletries claiming nano-sized $\mathrm{Pt}, \mathrm{Au}$ and $\mathrm{Ag}$ added. It is not always clear from additive notations how much these metallic elements are added. There are some papers on elemental analysis of cosmetics by instrumental neutron activation analysis (INAA) [4, 5], however, there have been only a few papers reported in the literature on elemental analysis of toiletries by neutron activation [6]. The INAA is considered suitable for analyzing the toiletries which were claimed to have the additives of $\mathrm{Pt}, \mathrm{Au}$ and $\mathrm{Ag}$ and some other elements in the negative list because of its non-destructive sample preparation step. Furthermore, there is inductively coupled plasma- mass spectrometry (ICP-MS) as a method to analyze metallic elements with high sensitivity, which, however, requires a sample dissolution step. Trace metallic elements in toiletries are considered to be detectable with high sensitivity by putting these two methods together. Furthermore, the metallic particles in toiletries can be inspected for the sizes by scanning electron microscope (SEM) and qualitatively analyzed for the kinds of elements by energy dispersive X-ray spectroscopy (EDX).

The purposes of this study are quantitative analyses of added metallic elements and some additives without notation in toiletries by INAA and ICP-MS and survey the size and kinds of included elements by SEM-EDX and to clar- 
ify the problems involved in the notation of toiletries and cosmetics.

\section{Experimental}

\subsection{INAA}

The analyzed toiletries claiming inclusion of $\mathrm{Pt}, \mathrm{Au}$ and $\mathrm{Ag}$ were collected randomly from Japanese cosmetics shops, ten cents shops and the Internet shops. A list of analyzed toiletries with their information is shown in Table 1. All 16 kinds of toiletries are produced in Japan. The number of samples containing Pt were 11, the Au were 5 and the $\mathrm{Ag}$ were 3 with some overlaps. Five kinds of samples were used as standard; chemical reagents of $\mathrm{Pt}, \mathrm{Au}$ and $\mathrm{Ag}$ for atomic absorption spectra (Wako Pure Chemical Industries) and two kinds of rock reference samples of JA-2 and JR -2 (GSJ; Geological Survey of Japan) [7].

Sample preparation was as follows; toiletries and chemical regents were absorbed in at most 5 sheets of filter paper (ADVANTEC 5A, $\varnothing 16 \mathrm{~mm}$ : ADVANTEC MFS, INC) and dried up by heating under an infrared lamp, then enclosed in polyethylene bags in 2 folds. The rock standard samples were enclosed with polyethylene bags in 2 folds. Triplicate samples of each toiletries and standards were irradiated. The weight of each sample ranged from 150 to $300 \mathrm{mg}$.

All the samples were put in one polyethylene capsule and irradiated in JRR-3 reactor (JAEA; Japan Atomic Energy Agency) for $10 \mathrm{~min}$ at a neutron flux of $5.2 \times 10^{13} \mathrm{n} \mathrm{cm}^{-2} \mathrm{~s}^{-1}$. After irradiation of the samples, they were left for appropriate cooling time of 2 days and then the capsule was opened. Each sample was enclosed in a new polyethylene bag and measurements of their gamma-ray spectra were carried out at the cooling time of 2 days, about 15 days and 6 months after the end of the irradiation.

The gamma-ray spectrometry of the irradiated samples was performed using a HPGe coaxial detector with an efficiency of $30 \%$ relative to $\mathrm{NaI}$, and with a $\mathrm{FWHM}=1.85 \mathrm{keV}$ at gamma-line $1330 \mathrm{keV}$. The auto sample changer of ASC-
20 (the Inter-University Laboratory, JAEA) was used which allowed to measure 20 samples in succession. The measurement time was from 300 to $30000 \mathrm{sec}$. depending on the induced activities of the samples. Elements were determined by measuring radioactivities of ${ }^{110 \mathrm{~m}} \mathrm{Ag},{ }^{198} \mathrm{Pt} \rightarrow{ }^{199} \mathrm{Au}$ and ${ }^{198} \mathrm{Au}$. Other elements determined were strontium $(\mathrm{Sr})$, zirconium ( $\mathrm{Zr})$, zinc $(\mathrm{Zn})$, arsenic (As) and chromium $(\mathrm{Cr})$. The detection limit of each nuclide was defined in this work as 3 times of the standard deviation (SD) of the sum of the $\mathrm{BG}$ values in the channels corresponding to the photon peak position. The error is based on the counting statistics. The analysis of spectra was performed by the software of "GAMA-08" [8].

\subsection{ICP-MS}

Among the 16 samples, Code Nos. 1, 5, 8, 9, 10 and 15 in the Table 1 were also analyzed by ICP-MS (Agilent Technologies, 7500a). For comparison, 4 kinds of "gold" metal samples of various purities and one kind of "silver" metal sample were analyzed with toiletries. The liquid or gel samples, 0.13-0.62 g, weighed in a PFA container and dissolved in super pure nitric acid and hydrochloric acid (Tama Chemical Industry, super high purity chemical reagent AA -100). The dissolved reagents were diluted over 100 times or more depending on the element concentrations in questions to be analyzed. Three sub-samples were prepared; each solution was first measured for $\mathrm{Pt}, \mathrm{Au}$ and $\mathrm{Ag}$, then, concentrations of other 6 heavy metals, i.e. $\mathrm{Cr}, \mathrm{Zn}, \mathrm{As}, \mathrm{Sr}, \mathrm{Cd}$ and $\mathrm{Pb}$, were measured with another quantitative measurement mode. The standard samples for making a calibration curve were prepared by adjusting the mixture of chemical reagents of the XSTC-7 and XSTC-13 (SPEX CertiPrep) with Milli-Q water (Millipore).

\subsection{SEM-EDX}

Among the 16 samples, Code Nos. 1, 5 and 8 were analyzed by SEM-EDX (Model JSM 6700F). Small pieces of shining particles were visible in the sample Code No. 5 and they

Table 1. Characteristics of the samples.

\begin{tabular}{|c|c|c|c|}
\hline \multicolumn{2}{|c|}{ Type of toiletries } & \multirow{2}{*}{$\begin{array}{c}\text { Price } \\
\text { (US } \$ \mathrm{~g}^{-1} \text {-sample) }\end{array}$} & \multirow{2}{*}{$\begin{array}{l}\text { Status } \\
\text { Specialty claimed by manufactures }\end{array}$} \\
\hline Code & Type & & \\
\hline 1 & Lotion & 0.2 & \multirow{3}{*}{$\begin{array}{l}\text { Nano-colloid of Pt and Ag } \\
\text { (Products of the same manufacture) }\end{array}$} \\
\hline 2 & Liquid cosmetics & 0.3 & \\
\hline 3 & Skin cream & 0.5 & \\
\hline 4 & Skin cream & 3.6 & \multirow{6}{*}{$\begin{array}{l}\text { Pt-nano-silica } \\
\mathrm{Au} \text { (visible) } \\
\text { Nano-colloid of Pt } \\
\text { Nano-colloid of Pt } \\
\text { Nano-sized Pt } \\
\text { Nano-sized Pt }\end{array}$} \\
\hline 5 & Beauty gel & 0.2 & \\
\hline 6 & Skin cream & 0.2 & \\
\hline 7 & Skin cream & 0.8 & \\
\hline 8 & Liquid cosmetics & 3.0 & \\
\hline 9 & Liquid cosmetics & 1.7 & \\
\hline 10 & Skin cream & 2.7 & \multirow{3}{*}{$\begin{array}{l}\text { Pt nano-colloid fullerene } \\
\text { (Products of the same manufacture) }\end{array}$} \\
\hline 11 & Liquid cosmetics & 2.0 & \\
\hline 12 & Lotion & 0.5 & \\
\hline 13 & Gel & 0.6 & Au: 24 Gold leaf (visible) \\
\hline 14 & Cleansing gel & 0.3 & \multirow{3}{*}{$\begin{array}{l}\text { Nano-sized Au } \\
\text { (Products of the same manufacture, } \\
\text { sample No. } 14 \text { and } 16 \text { include visible } \\
\text { shining particles.) }\end{array}$} \\
\hline 15 & Lotion & 0.3 & \\
\hline 16 & Skin cream gel & 1.2 & \\
\hline
\end{tabular}


were selected for observation by SEM. Other liquid samples Code Nos. 1 and 8 which had no visible particles were randomly selected by pipetting. The sample was placed on a carbon plate and measured with the acceleration voltage; $15 \mathrm{kV}$.

\section{Results}

The concentrations of 3 elements in the standard reference rock samples determined by INAA are shown in Table 2 . The analyzed concentrations agreed well with the certified values, and thus, the data by INAA obtained in the present work were found quantitatively reliable.

The concentrations of $\mathrm{Pt}, \mathrm{Au}$ and $\mathrm{Ag}$ in the toiletries were analyzed by INAA and ICP-MS as shown in Table 3. The concentrations in Table 3 written with the bold letters were the elements that each manufacturer claimed to have added in the toiletries. The concentrations of $\mathrm{Pt}, \mathrm{Au}$ and $\mathrm{Ag}$ in the toiletries determined by ICP-MS were in good agreement with those obtained by INAA. However, the concentrations of $\mathrm{Au}$ in some Au samples differed in some cases by these two methods. The reason is discussed in Discussion below.

For INAA, the range of concentrations of the added $\mathrm{Pt}$ in the samples was $1 \sim 80 \mathrm{ppm}$. Some samples, e.g. sample Code No. 4, contained a large amount of sodium (Na), and the produced activities of ${ }^{24} \mathrm{Na}$ ( $14 \mathrm{~h}$ half life) pushed up the detection limits of other nuclides such as $\mathrm{Pt}$ and $\mathrm{Au}$. So, in the samples Code Nos. 4, 6, 7 and 12, the concentrations of Pt claimed to be added in them were equal to or less than the respective detection limits of the samples.

The size of Pt in the sample Code No.8, which was claimed to be added as nano-sized Pt particles, was almost
Table 2. Accuracy of the present method of INAA.

\begin{tabular}{|c|c|c|c|}
\hline \multirow[t]{2}{*}{ Value } & \multicolumn{3}{|c|}{ Concentration (ppm) } \\
\hline & $\begin{array}{c}\mathrm{Cr} \\
(320 \mathrm{keV})\end{array}$ & $\begin{array}{c}\mathrm{Zn} \\
(1115 \mathrm{keV})\end{array}$ & $\begin{array}{c}\mathrm{Zr} \\
(724 \mathrm{keV})\end{array}$ \\
\hline Measured & $2.93 \pm 0.22^{a}$ & $25.2 \pm 0.7^{a}$ & $110 \pm 12^{b}$ \\
\hline Certified & 3.10 & 27.8 & 116 \\
\hline
\end{tabular}

a: The certified values of JA-2 [7] were used as standards; b: The certified value of JR-2 [7] was used as a standard.

$200 \times 200$ nanometers according to the analysis by SEMEDX as shown in Fig. 1. On the other hand, Pt was not detectable by SEM in the sample Code No.1 in which Pt and $\mathrm{Ag}$ were claimed to be added as nano-colloids.

In the sample Code Nos. 5, 13, 14 and 16, many shiny small pieces could be observed visibly by eyes. The pieces in the sample Code No. 5 were found to be Au analyzed by SEM-EDX as shown in Fig. 2. Furthermore, in the same sample Code No. $5, \mathrm{Cu}$ was surveyed qualitatively which however could not be analyzed quantitatively by INAA because of the high BG caused by ${ }^{24} \mathrm{Na}$. Moreover, the concentrations of $\mathrm{Au}$ in the sample Code Nos. 5, 13, 14 and 16 showed some wide ranges which indicated the nonuniformity in the gel samples. There is no visible "Au" in the toiletries of Code Nos. 14, 15 and 16 to which the manufactures claimed to have added the nano-sized Au. Analysis by INAA and ICP-MS, these invisible Au samples included almost $18 \mathrm{ppm}$ of $\mathrm{Au}$.

The concentration range of $\mathrm{Ag}$ in three samples of Code Nos. $1 \sim 3$ that the manufactures claimed to have added was 90 $120 \mathrm{ppb}$. The concentrations of $\mathrm{Ag}$ in the toiletries

Table 3. Concentrations of $\mathrm{Pt}, \mathrm{Au}$ and $\mathrm{Ag}$ in toiletries.

\begin{tabular}{|c|c|c|c|c|c|c|}
\hline \multirow{3}{*}{$\begin{array}{l}\text { Sample } \\
\text { Code }\end{array}$} & \multirow{2}{*}{\multicolumn{2}{|c|}{$\mathrm{Pt}$}} & \multirow{2}{*}{\multicolumn{2}{|c|}{ Concentration (ppm) }} & \multirow{2}{*}{\multicolumn{2}{|c|}{$\mathrm{Ag}$}} \\
\hline & & & & & & \\
\hline & INAA & ICP-MS & INAA & ICP-MS & INAA & ICP-MS \\
\hline 1 & $1.6 \pm 0.2$ & $1.5 \pm 0.04$ & $<0.001$ & $0.06 \pm 0.06$ & $0.12 \pm 0.02$ & $0.12 \pm 0.01$ \\
\hline 2 & $1.3 \pm 0.2$ & - & $<0.001$ & - & $0.09 \pm 0.02$ & - \\
\hline 3 & $2.4 \pm 0.3$ & - & $<0.002$ & - & $0.09 \pm \mathbf{0 . 0 2}$ & - \\
\hline 4 & $<4$ & - & $<0.006$ & - & $<0.05$ & - \\
\hline $5^{*}$ & $<14$ & $(<32)^{* *}$ & $150-280$ & $7.7-430$ & $0.9 \pm 0.08$ & $1.7 \pm 1.1$ \\
\hline 6 & $<2$ & - & $<0.003$ & - & $<0.03$ & - \\
\hline 7 & $<1$ & - & $<0.001$ & - & $<0.05$ & - \\
\hline 8 & $79 \pm 3$ & $94 \pm 5$ & $<0.001$ & $<4.2$ & $<0.07$ & $(<1.7)^{* *}$ \\
\hline 9 & $3.3 \pm 0.3$ & $3.5 \pm 0.3$ & $<0.002$ & $0.08 \pm 0.04$ & $<0.03$ & $(<1.7)^{* *}$ \\
\hline 10 & $22 \pm 1.2$ & $\mathbf{3 1} \pm \mathbf{3}$ & $<0.002$ & $<7.5$ & $<0.07$ & $<0.2$ \\
\hline 11 & $0.9 \pm 0.2$ & - & $<0.001$ & - & $<0.03$ & - \\
\hline 12 & $<1$ & - & $<0.002$ & - & $<0.03$ & - \\
\hline $13^{*}$ & $<3$ & - & 29-220 & - & $1.0-6.1$ & - \\
\hline 14 & $<6$ & - & 53-208 & - & $1.1-6.6$ & - \\
\hline 15 & $<3$ & $<0.1$ & $19 \pm 0.3$ & $18 \pm 4.8$ & $0.5-1.0$ & $1.1 \pm 0.2$ \\
\hline 16 & $<5$ & - & $120-260$ & - & $6.9-13$ & - \\
\hline
\end{tabular}

Bold: The element(s) that manufactures claimed to have added to the sample.

$<$ : Lower than the detection limit cited.

- : Not measured.

\pm : Error based on the counting statistics by INAA, and standard deviation of the observed data among 2-3 samples for ICP-MS.

*: These samples included many shiny small pieces, so the concentrations of $\mathrm{Au}(\mathrm{Ag}) \mathrm{had}$ some ranges depending on whichever sections of toiletries were used as the analysis samples.

**: The unit is "ppt". 

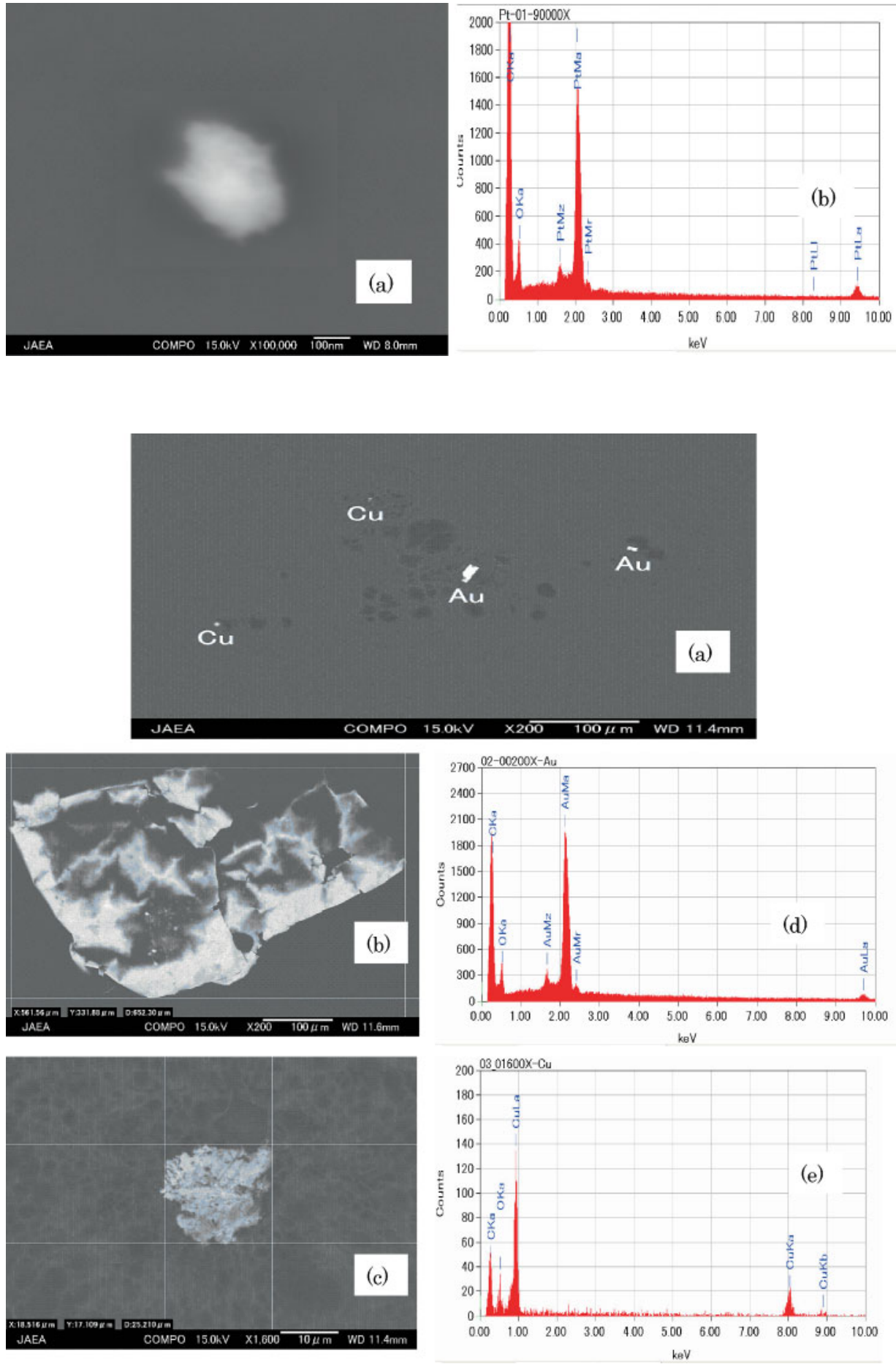

Fig. 1. Photos of sample Code No. 8 by SEM (a) and the X-ray spectrum (b) of the particle in the center of photo (a) scanned by EDX. The particle size of Pt was almost $200 \times 200$ nanometers in the sample Code No. 8.
Fig. 2. Photos of sample Code No. 5 by SEM (a)-(c) and the X-ray spectra (d) and (e). The (a) showed a wide range of photo and 2 elements of $\mathrm{Cu}$ and Au were detected by SEM-EDX. The particle size of photo (b) was almost $300 \times 300$ micrometers, and the $\mathrm{X}$ ray spectrum (d) of photo (b) showed that the particle was Au. Also copper was detected in the same sample as the size of almost $10 \times 10$ micrometers as shown in photo of (c) and the X-ray spectrum of (e). show significantly lower by 1-3 orders of magnitude than those of $\mathrm{Pt}$ and $\mathrm{Au}$.

The concentrations of $\mathrm{Ag}$ in $5 \mathrm{Au}$ samples of Code Nos. 5, 13 16 were higher than those of the Ag samples of No. $1 \sim 3$ to which they claimed addition of Ag. The toiletries in which $\mathrm{Ag}$ were included without notation tend to be cheap in their unit price (Table 1). The Ag found in the $\mathrm{Au}$ added toiletries is probably included as impurities of the low purity $\mathrm{Au}$ added by INAA analysis. In order to prove that the Ag is impurity in Au, gold and silver metal samples as mentioned above were analyzed by ICP-MS. Among the silver was not detected in the super high purity gold, however, silver was considerably included in the moder- ate purity gold (almost $0.1 \%$ ) and the gold leaf used for Japanese art (almost 5\%). Moreover, it was also confirmed that gold was included in the silver leaf used for Japanese art (almost 2\%).

The concentrations of some other metal elements observed by INAA and ICP-MS are shown in Table 4. Though $\mathrm{Sr}$ is nominated in the negative list, $\mathrm{Sr}$ was certainly detected in 2 kinds of toiletries by ICP-MS. Furthermore, $\mathrm{Pb}$ was also detected in the same 2 kinds of toiletries in which $\mathrm{Sr}$ was detected by ICP-MS. The addition limit of As for toiletries and cosmetics is confined to less than $2 \mathrm{ppm}$ in Japanese "The Drugs, Cosmetics and Medical Instruments Act", which is the only metallic element the addition limit 
Table 4. Concentration of some elements in toiletries.

\begin{tabular}{lcccc}
\hline \multicolumn{5}{c}{ Concentration } \\
$\begin{array}{l}\text { Method } \\
\text { Sample } \\
\text { code }\end{array}$ & \multicolumn{2}{c}{ INAA (ppm) } & \multicolumn{2}{c}{ ICP-MS (ppb) } \\
& & & $\mathrm{Sr}$ & $\mathrm{Pb}$ \\
\hline 1 & 0.5 & 0.2 & 1 & 34 \\
2 & 0.5 & 0.1 & - & - \\
3 & 0.5 & 0.1 & - & - \\
5 & 0.7 & $<0.4$ & $<0.002$ & $<0.005$ \\
6 & 0.5 & 0.1 & - & - \\
7 & 1.0 & $<0.1$ & - & - \\
8 & 0.4 & $<0.1$ & $<0.002$ & $<0.005$ \\
9 & 3.9 & 0.2 & 130 & 9 \\
10 & 0.5 & $<0.1$ & $<0.002$ & $<0.005$ \\
11 & 0.1 & 0.1 & - & - \\
\hline
\end{tabular}

$<$ : Lower than the detection limit cited.

-: Not measured.

is clearly defined. Since the detection limit of $\mathrm{As}\left({ }^{76} \mathrm{As}\right)$ by INAA was $0.1 \sim 1.3 \mathrm{ppm}$ and no meaningful quantity of As was detected, we could confirm that no As was added to these toiletries. Also, observation of $\mathrm{Cd}$ and $\mathrm{Hg}$, poisonous elements, were attempted by ICP-MS in these samples, they were not detected with the detection limits of 8 and $68 \mathrm{ppt}$, respectively.

\section{Discussion}

In this study, it was found that the sample preparation method of simply putting each toiletry on filter paper without more special preprocessing was clearly suitable for getting enough sensitivity for INAA analysis of toiletries.

Two methods of INAA and ICP-MS were used for quantitative analysis in this study. For some toiletries, it was difficult to keep uniformity of the sample preparation especially in the sample including nano-particles. It is considered that keeping the uniformity for sample preparation is particularly difficult when the concentrations of target elements are not high. Because a large quantity of sample $(150 \sim 300 \mathrm{mg}$ ) was used for INAA, an influence of non-uniformity of sample could be avoided. On the other hand, for qualitative analysis by ICP-MS, a small amounts of sample is used for each determination. When small particles cannot be completely dissolved by acid for ICP-MS, keeping uniformity of sample was difficult and a large scattering of data was observed among 5 samples. Therefore, it is necessary to find a technique to dissolve the uniform sample containing nano-particles for ICP-MS method.

Because $\mathrm{Na}$ is necessarily included in toiletries, the detection of elements included in toiletries which produced short and/or middle half life nuclides by irradiation is not so easy in INAA. Although 11 samples of toiletries were claimed to have Pt added, 4 samples were equal to or less than the detection limits. The reason of undetected Pt is probably that the background levels were pushed up by influence of $\mathrm{Na}$ in toiletries.

The amounts of Ag in gold metal sample could not be determined by INAA because the thermal neutron cross sec- tion of Au was extremely high. The ICP-MS method is suitable for this purpose. Furthermore, Sr nominated in the negative list was detected in 2 samples by ICP-MS, but not by INAA.

Because the detection of extremely small amounts of elements has become practically possible by the progress of analytical methods, it is necessary to revise the regulation limits in accordance with the progress. The negative list which must not be detected even as impurities becomes meaningless unless minimum allowable limits are specified. Though the heavy metal of $\mathrm{Pt}, \mathrm{Au}$ and $\mathrm{Ag}$ are added in toiletries claiming a beauty effect, it is considered that $\mathrm{Ag}, \mathrm{Sr}$ and some other miner elements have become included as impurities in toiletries because of the addition of these heavy metals. It is hard to get user's support for the benefit from a certain effect if the risk is brought about by addition of the heavy metal.

The elements nominated in the negative list and the positive list of Japan were analyzed. Because impurities in toiletries nominated in these 2 lists were not detected except in 2 samples, it is possible that refined raw materials were used for these toiletries. Ag as impurity of Au was detected in some toiletries, however, Ag has no problem because the element of $\mathrm{Ag}$ is not nominated in those lists. However, because the impurities of $\mathrm{Ag}$ were contained in the toiletries more than the quantity added to them as additives of toiletries, it is supposed that the manufactures have not analyzed the purity of the additives before sale. Furthermore, it is considered that the contents of impurities in toiletries change in each lot, so that the spot check test of toiletries and cosmetics is necessary to keep the quality of them. So it is desired to invent a simple, easy and cheap analytical method of toiletries for routine work. At this point, it is considered that the qualitative analytical method of SEM-EDX is suitable for analyzing toiletries and cosmetics because the sample preparation method is not so complex.

The quantitative indication of the ingredients in toiletries and cosmetics is not requested because of business secrets. In some case, there was a difference of an order of magnitude in the concentrations of $\mathrm{Pt}$ and $\mathrm{Ag}$, which were added to each toiletry together. The difference of the quantity of the elements added is not mentioned in the advertisement. The quantitative description of elements added in a toiletry should be required by law.

In addition, there was no correlation between the unit prices (Table 1) and the content concentrations (Table 3). The main additive which was advertized for the beauty effect of the toiletry did not push up the price.

\section{Conclusion}

Metallic elements in toiletries were analyzed by the instrumental neutron activation analysis (INAA) and the inductively coupled plasma-mass spectrometry (ICP-MS) and surveyed the particle sizes by scanning electron microscopeenergy dispersive X-ray spectroscopy (SEM-EDX). The samples for INAA were prepared by putting the toiletries on several sheets of filter paper and drying under an infrared lamp. Because of the coexistence of large amounts 
of activated $\mathrm{Na}$, the detection limits of platinum $(\mathrm{Pt})$, gold $\mathrm{Au})$ and silver $(\mathrm{Ag})$ in the present case of INAA were $0.4 \sim 14 \mathrm{ppm}, 0.7 \sim 22 \mathrm{ppm}$ and $20 \sim 80 \mathrm{ppb}$, respectively. On the other hand, the sample for ICP-MS was prepared by dissolving the toiletries in nitric acid and hydrochloric acid. The detection limits of $\mathrm{Pt}, \mathrm{Au}$ and $\mathrm{Ag}$ by this case of ICP-MS were 32, 66 and $1.7 \mathrm{ppt}$, respectively. In some toiletries which claimed $\mathrm{Pt}$ added, the concentrations of Pt were under the detection limits by INAA. It was also difficult to detect the nano-sized Pt by SEM-EDX although it might have been added. One toiletry claimed to be added the nano-sized $\mathrm{Pt}$, the particle size of $\mathrm{Pt}$ was almost $200 \mathrm{~nm}$ by SEM-EDX. On the other hand, in some toiletries which claimed $\mathrm{Au}$ added, $\mathrm{Ag}$ was detected in them and the existence of impurities became clear. Furthermore, strontium, which is nominated in the negative list, and lead were detected in 2 samples by ICP-MS. Extremely low concentration of element is now detectable by the progress of the analytical methods. So it is suspected that the manufactures have not analyzed the purity of additives of the toiletries before sale. It is concluded that the merit and the risk of adding heavy metals in toiletries should be reconsidered as special caution because they are applied to skin directly.
The neutron activation analysis has been carried out at the Inter-University Laboratory for the Joint use of JAEA Facilities.

\section{References}

1. UNCED, Environmentally Sound Management of Toxic Chemicals, including Prevention of Illegal International Traffic in Toxic and dangerous Products, Agenda 21, Chapter 19 (2004).

2. EU Directive 76/768/EEC, Cosmetics legislation V.1 (1999).

3. Council for medicine 163, About an indication method of ingredients of cosmetics (2001) (in Japanese).

4. E. A. A. El-Shazly, Sh. F. Abo Zahra, F. H. El-Sweify and G. D. Kanias: Simultaneous multi-element determination in some cosmetic samples of different origins using neutron activation analysis. Radiochim. Acta 92, 111-117 (2004).

5. G. Misra and K. Mittal: Neutron activation analysis of lipsticks using $\gamma$-ray spectrometry. J. Appl. Spectrosc. 71, 270-274 (2004),

6. E. Furuta, H. Nakahara, Y. Hatsukawa, H. Matsue, and H. Sakane: Neutron activation analysis of trace elements in Japanese hormisis cosmetics. J. Radioanal. Nucl. Chem. 278, 553-557 (2008).

7. N. Imai, S. Terashima, S. Itoh and A. Ando: Compilation of analytical data for minor and trace elements in seventeen GSJ geochemical reference samples, "igneous rock series". Geostand. Newslett. 19, 135-213 (1995)

8. S. Suzuki and S. Inoshita; Development of gamma-ray spectrum analysis program for activation analysis. Radioisotopes 157, 429435 (2008). 